\section{Charity hospital wins research award}

Aniko Balazs, Dental Nurse Manager for the Royal Hospital for Neuro-disability, has been granted a Colgate-Palmolive Dental Care Professional (DCP) Research award for $£ 2,500$.

The Royal Hospital for Neuro-disability is an independent national medical charity based in Putney, South-West London. The hospital specialises in assessing and rehabilitating adults with traumatic brain injuries incurred through accidents or strokes. It also provides both treatment and long-term care for people with severe and complex neurological conditions.

The funds will enable support for the involvement of a dental hygienist to strengthen the current Oral Care Link Nurse scheme, which is in operation on all the hospital's wards. Aniko has worked at the charity hospital for just over a year. She said, 'This award is incredibly important, both to the dentistry department and to the hospital as a whole. It will allow us to continue to improve our patient-led care, and help us to work more easily in conjunction with ward staff.

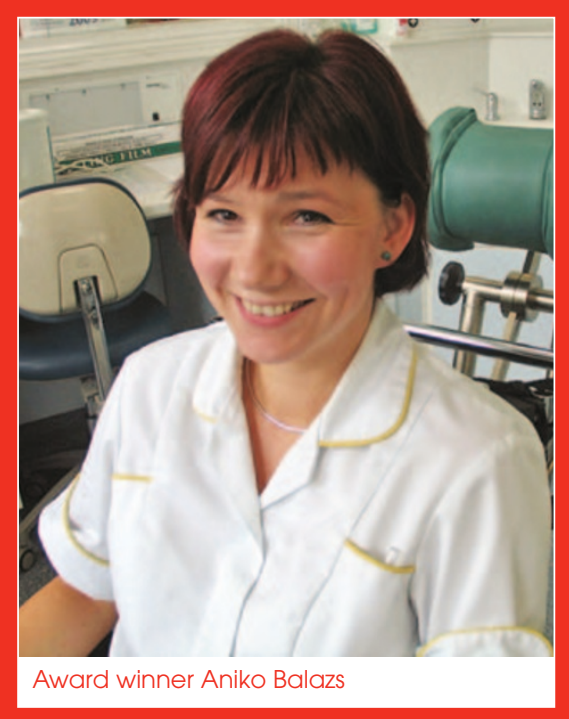

The hygienist will work with the Oral Care Link Nurses to ensure that specific patient based oral hygiene programmes are developed, enabling patients to receive individual regimes that are specific to them. The scheme also aims to make patient oral hygiene a daily routine of ward duties.

\title{
New Patron
appointed
}

The National Oral Health Promotion Group (NOHPG) has appointed a new Patron. The Group's members invited Catherine Stillman-Lowe, independent oral health promotion advisor, to take up the honorary position for the next three years.

Known to many as co-author of The scientific basis of oral health education, published by BDJ Books, Cathy said, 'It is a great honour to be asked to support the NOHPG by taking on this role. The Group provides a valuable service to its members by promoting evidence-based oral health promotion, and advocating policies that will result in sustainable improvements in oral

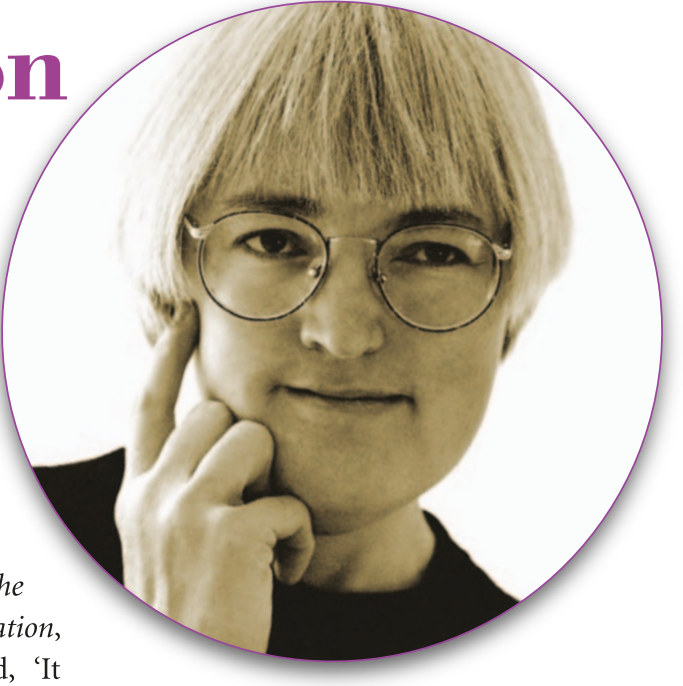

health. By sharing good practice between oral health promoters across the UK, the Group helps to reduce professional isolation and raise standards at the grassroots level'.

\section{New}

\section{aliploma for technicians}

\section{approved}

The Faculty of General Dental Practice (UK), working with the Kent, Sussex and Surrey (KSS) Deanery, has been given the go-ahead by the General Dental Council (GDC) to progress a route to registration for clinical dental technicians (CDTs).

There are currently no approved awards in clinical dental technology offered in the UK, however, there are a significant number of dental technicians working in the UK today who hold qualifications in this field from the George Brown College in Toronto.

The new route to registration will allow those with George Brown awards to undertake extra training, provided through KSS, leading to an FGDP (UK) Diploma in Clinical Dental Technology.

The CDT is a new role that is being introduced to the dental team to coincide with the DCP Register, which opened at the end of July. CDTs will be able to see edentulous patients without prior review by a dentist. Work is now underway to establish a process for the training and assessment of potential CDTs from this group.

For further information or to register an interest in the diploma, please contact Sally Hunter, FGDP (UK) Development Officer, on 02078696766 or shunter@rcseng.ac.uk.

\section{Statutory register opens}

The new statutory register for dental care professionals (DCPs) practising in the UK opened in July. Dentists, dental hygienists and dental therapists are already registered with the GDC and now, other professionals who play a role in patients' dental care, including dental nurses and dental technicians, will join the GDC's registers. Registration means that dental professionals have met educational standards and that they are professionally accountable for their actions. 